Full length article

\title{
An integrative analysis of chemically-induced cirrhosis-associated hepatocarcinogenesis: Histological, biochemical and molecular features
}

\author{
Guilherme Ribeiro Romualdo ${ }^{\mathrm{a}}$, Tony Fernando Grassi ${ }^{\mathrm{b}}$, Renata Leme Goto ${ }^{\mathrm{b}}$, \\ Mariana Baptista Tablas ${ }^{\mathrm{b}}$, Lucas Tadeu Bidinotto ${ }^{\mathrm{c}, \mathrm{d}}$, Ana Angélica Henrique Fernandes ${ }^{\mathrm{e}}$, \\ Bruno Cogliati ${ }^{\mathrm{f}}$, Luís Fernando Barbisan ${ }^{\mathrm{b}, *}$ \\ a Department of Pathology, Botucatu Medical School, São Paulo State University (UNESP), Botucatu - SP, Brazil \\ b Department of Morphology, Institute of Biosciences, São Paulo State University (UNESP), Botucatu - SP, Brazil \\ ${ }^{\mathrm{c}}$ Molecular Oncology Research Center, Barretos Cancer Hospital, Barretos - SP, Brazil \\ d Barretos School of Health Sciences, Dr. Paulo Prata - FACISB, Barretos - SP, Brazil \\ e Department of Chemistry and Biochemistry, Institute of Biosciences, São Paulo State University (UNESP), Botucatu - SP, Brazil \\ ${ }^{\mathrm{f}}$ Department of Pathology, School of Veterinary Medicine and Animal Science, São Paulo University (USP), São Paulo - SP, Brazil
}

\section{G R A P H I C A L A B S T R A C T}

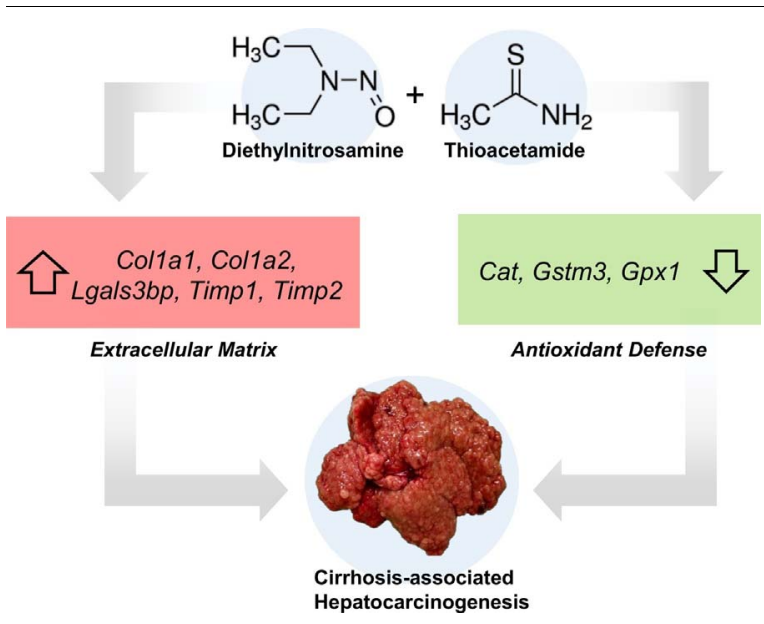

\section{A R T I C L E I N F O}

\section{Keywords:}

Hepatocarcinogenesis

Liver cirrhosis

Diethylnitrosamine

Thioacetamide

Oligo microarray

Wistar rats

\begin{abstract}
A B S T R A C T
This study aimed the integrative characterization of morphological, biochemical and molecular features of chemically-induced cirrhosis-associated hepatocarcinogenesis. Thus, male Wistar rats were submitted to a diethylnitrosamine (DEN)/thioacetamide (TAA)-induced model. Liver tissue was processed for global gene expression, histopathological and collagen evaluations; as well as immunohistochemical and oxidative stress analysis. Gene Ontology and functional analysis showed the upregulation of extracellular matrix deposition genes, such as collagen type I alpha 1 and 2 (Col1 $\alpha 1$ and Col1 $\alpha 2$ ) and tissue inhibitor of metalloproteinase 1 and 2 genes (Timp1 and Timp2). In agreement these findings, animals presented extensive liver cirrhosis with increased collagen deposition (Sirius red). Besides, the animals developed many glutathione S-transferase pi (GSTP)-positive preneoplastic lesions showing high cell proliferation (Ki-67), in keeping with the Gstp1 and Gstp2
\end{abstract}

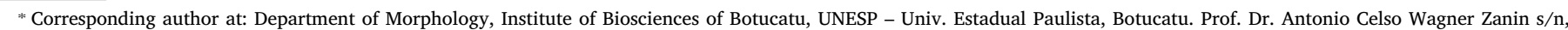
18618-689, Botucatu, SP, Brazil.

E-mail address: barbisan@ibb.unesp.br (L.F. Barbisan). 
increased gene expression. DEN/TAA-treated rats also showed the upregulation of tumorigenesis-related annexin A2 gene (Anxa2) and few neoplastic lesions (hepatocellular adenomas, carcinomas, and cholangiocarcinoma). In contrast, gene expression and activity of antioxidant enzymes were decreased (glutathione peroxidase, total glutathione-S-transferase, and catalase). The model featured remarkable similarities to human hepatocarcinogenesis. Our findings could bring up new molecular insights into cirrhosis-associated hepatocarcinogenesis, and provide a suitable animal model for the establishment of further diagnostic, preventive and therapeutic approaches.

\section{Introduction}

The hepatocellular carcinoma (HCC) is the most common type of primary liver cancer and is considered a complex, multistep and multifactorial disease (Sanyal et al., 2010). The HCC is responsible for, approximately, 800.000 newly diagnosed cases and deaths per year worldwide (GLOBOCAN, 2013). This cancer usually emerges in a background of cirrhotic tissue ( $\sim 70-90 \%$ of cases), mainly caused by chronic liver diseases linked to chronic hepatitis B and C virus infections and chronic ethanol intake (Sanyal et al., 2010; Yang et al., 2011). Cirrhosis, the end-stage of liver disease, is associated with high morbidity and mortality indexes worldwide (Mokdad et al., 2014; Scaglione et al., 2015), and was responsible for more than one million of deaths around the world in 2010 (Mokdad et al., 2014). The drastically altered microenvironment in the cirrhotic liver predisposes to several genetic and epigenetic alterations that can promote the development of preneoplastic or neoplastic lesions, mainly HCC (Zhou, 2014).

Considering the importance of chronic inflammatory microenvironment in the pathogenesis of HCC, different chemically-induced rodent models of fibrosis/cirrhosis and/or hepatocarcinogenesis are widely applied in translational research since they mimic some of the human disease features, including histopathology and clinical outcomes (Bakiri and Wagner, 2013; De Minicis et al., 2013; Yanguas et al., 2015). Diethylnitrosamine (DEN) is mainly used as an initiating agent of rodent hepatocarcinogenesis while the thioacetamide (TAA) is frequently applied for inducing liver fibrosis/cirrhosis, establishing a promoting environment to DEN-induced lesions (Ito et al., 2000; Wallace et al., 2015). The hepatic bioactivation of DEN generates reactive metabolites and reactive oxygen species (ROS), which lead to the formation of mutagenic DNA adducts (Qi et al., 2008). In addition, the bioactivation of TAA produces reactive metabolites which bind proteins and lipids thereby causing oxidative stress, centrilobular necrosis and, ultimately, hepatic stellate cell (HSC) activation and collagen deposition (Wallace et al., 2015). This altered hepatic microenvironment of increased oxidative stress, genome instability and HSC activation in rodents resembles human cirrhosis-associated hepatocarcinogenesis (Cichoż-Lach and Michalak, 2014).

Previous studies provided data on the global proteomic profile of cirrhotic microenvironment in TAA-treated rats, as well as on the global gene expression of DEN-induced cirrhosis-associated hepatocarcinogenesis in rats, in order to explain the molecular events involved in the progression of preneoplastic liver nodules into HCC (Low et al., 2004; Liu et al., 2009). Nonetheless, most of these studies lack on associating the molecular alteration profile to the subsequent biochemical and morphological alterations during cirrhosis-associated hepatocarcinogenesis.

Therefore, we aimed the integrative characterization of the molecular, morphological, and biochemical aspects of chemically-induced cirrhosis-associated hepatocarcinogenesis, featuring its many similarities to the human disease. The characterization of this model could also bring up new molecular insights into cirrhosis-associated hepatocarcinogenesis, as well as provide a standard rodent model for the establishment of diagnostic, preventive and therapeutic approaches for hepatocarcinogenesis in humans.

\section{Materials and methods}

\subsection{Animals, treatments and sampling}

Four-week-old male Wistar rats were purchased from the Multidisciplinary Center for Biological Investigation (CEMIB, UNICAMP, Campinas, SP, Brazil). After a 2-week acclimatization period, the animals were randomly allocated into two groups ( $\mathrm{n}=10$ rats/group): a vehicle-treated group (untreated) and a group submitted to a classical chemically-induced cirrhosis-associated hepatocarcinogenesis model. This group received a single intraperitoneal (i.p.) injection of DEN [ $200 \mathrm{mg} / \mathrm{kg}$ body weight (b.wt.), in $0.9 \%$ saline] (SigmaAldrich, USA) (Ito et al., 2000), and two weeks later, the animals were submitted to six cycles of TAA (Furtado et al., 2012). During these cycles, animals received TAA twice a week $(200 \mathrm{mg} / \mathrm{kg}$ b.wt., i.p., in $0.9 \%$ saline) (Sigma-Aldrich, USA) during three weeks, and each cycle was followed by one week without treatment (Supplementary data 1). Animals were euthanized $24 \mathrm{~h}$ after the last TAA administration by exsanguination under ketamine/xylazine anesthesia (91 and $9.1 \mathrm{mg} / \mathrm{kg}$ b.wt., respectively). In terms of experimental design, considering that $70 \%$ to $90 \%$ of human HCC cases emerge in a cirrhotic background, the repeated administration of a fibrogenic agent instead of a non-fibrogenic promoting drug is recommended to induce hepatocellular lesions that resemble human pathology (Sanyal et al., 2010).

Body weight and food intake were measured weekly throughout the experimental period. The animals received a commercial chow (LABINA, Purina, Brazil) and water ad libitum and were housed in polypropylene cages in a room maintained at $22 \pm 2{ }^{\circ} \mathrm{C}, 55 \pm 10 \%$ humidity and with a 12-h light/dark cycle (light between 07:00 a.m. and 07:00 p.m.). The experiments were carried out under protocols approved by Institute of Biosciences/UNESP Ethics Committee on Use of Animals (CEUA) (Protocol number 1073/2014) and all animals received humane care according to the criteria outlined in the "Guide for the Care and Use of Laboratory Animals" (National Research Council, 2011).

\subsection{Tissue processing, histological and immunohistochemical procedures}

At necropsy, the liver was removed, washed with a saline solution $(0.9 \% \mathrm{NaCl})$, macroscopically examined for the occurrence of gross abnormalities and weighted. Representative liver samples were either fixed in $4 \%$ phosphate-buffered formalin during $24 \mathrm{~h}$ for paraffin embedding or frozen at $-80{ }^{\circ} \mathrm{C}$ for posterior molecular analyses. Paraffinembedded liver samples were sliced into $5-\mu \mathrm{m}$ thick sections and stained with hematoxylin-eosin (HE) for histopathological analysis according to well-established criteria (Thoolen et al., 2010). Other sections were stained by Sirius red for morphometric analysis of collagen content (Furtado et al., 2012). Lastly, the immunoexpression of glutathione S-transferase pi (GST-P, preneoplastic and neoplastic lesions marker), and Ki-67 (cell proliferation marker) was immunohistochemically detected in liver sections. Briefly, deparaffinated $5-\mu \mathrm{m}$ liver sections on silanized slides were treated sequentially with citrate buffer $\left(120^{\circ} \mathrm{C}, 5 \mathrm{~min}\right)$ in a Pascal Pressure Chamber (Dako Cytomation, Denmark), $3 \% \mathrm{H}_{2} \mathrm{O}_{2}$ in phosphate-buffered saline (PBS) (10 min) and nonfat milk (60 min). After, the slides were incubated with anti-Ki-67 (ab16667, 1:100 dilution, Abcam, UK) or anti-GST-P 
(clone 311, 1:1000 dilution, Medical and Biological Laboratories, Japan) antibodies overnight at $4{ }^{\circ} \mathrm{C}$ After, the biotinylated universal link and streptavidin HPR were applied according to the manufacturer's instructions (Dako Cytomation, Denmark). Chromogen color development was accomplished with 3,3'-diaminobenzidine tetrahydrochloride (DAB, Sigma-Aldrich, USA) and the slides were counterstained with Harriśs hematoxylin. For Ki-67 semiquantitative analysis, 40 random fields were assessed per section ( $40 \mathrm{x}$ objective), comprising all liver lobes. Ki-67-positive hepatocytes were counted and divided by the analyzed liver area $\left(\mathrm{mm}^{2}\right)$. For GST-P analysis, GST-P ${ }^{+}$foci and hyperplastic nodules were counted and classified in different size classes and divided by the analyzed liver area $\left(\mathrm{mm}^{2}\right)$. All analyses were performed on a Leica DMLB 80 microscope connected to a Leica DC300FX camera and the digitalized images were analyzed using the Leica Q-win software Version 3 (Leica, Germany).

\subsection{Gelatin zymography for matrix metalloproteinases 2 and 9 (MMP-2} and 9)

Frozen liver samples $\left(-80^{\circ} \mathrm{C}\right)$ were mechanically homogenized in $50 \mathrm{mM}$ Tris buffer $\mathrm{pH} 7.5$ plus $1 \%$ triton-X 100 and $\mathrm{CaCl}_{2} 10 \mathrm{mM}$ with a Polytron $\left(30 \mathrm{~s}\right.$ at $\left.4{ }^{\circ} \mathrm{C}\right)$, centrifuged and proteins extracted on supernatant were quantified by Bradford method. Aliquots ( $30 \mu \mathrm{g}$ protein) from liver extracts were subjected to electrophoresis in $8 \%$ polyacrylamide gel containing $0.1 \%$ gelatin in the presence of SDS under non-reducing conditions (Furtado et al., 2009). The gels $(0.75 \mathrm{~mm}$ thick) were electrophoresed $\left(2 \mathrm{~h}\right.$ at $\left.100 \mathrm{~V}, 4^{\circ} \mathrm{C}\right)$, in a Bio-Rad MiniProtean II system (Bio-Rad Laboratories, USA). Following electrophoresis, the gels were washed by gentle shaking at room temperature with $2.5 \%$ Triton X-100 (two changes) $(1 \mathrm{~h})$. The gels were incubated overnight $\left(16 \mathrm{~h}\right.$ at $\left.37^{\circ} \mathrm{C}\right)$ in $50 \mathrm{mM}$ Tris- $\mathrm{HCl}(\mathrm{pH}$ 8.4) containing $5 \mathrm{mM}$ $\mathrm{CaCl}_{2}$ and $1 \mu \mathrm{M} \mathrm{ZnCl}$. After incubation, the gels were stained by Coomassie Brilliant Blue R-250. Areas of proteolysis appeared as clear zones against a blue background. Molecular mass determinations were made with reference to prestained protein standards (Bio-Rad Laboratories) co-electrophoresed into the gels. The integrated optical density (IOD) spectrophotometry was determined in an Image Master VDS version 3.0 V (Pharmacia Biotechnology, USA). The values of IOD were statistically analyzed and plotted in histograms.

\subsection{RNA extraction and oligo microarrays}

Total RNA was isolated from the frozen liver samples using the RNeasy kit (QIAGEN, USA) according to the manufacturer's instructions. The extracted RNA was stored at $-80^{\circ} \mathrm{C}$. RNA was quantified in a spectrophotometer NanoVue (GE Healthcare, UK) and the integrity was evaluated using the Agilent 2100 Bioanalyzer (Agilent Technologies, USA) under standard conditions. An aliquot containing $150 \mathrm{ng}$ of total RNA was hybridized onto whole rat genome $4 \times 44 \mathrm{~K}$ oligo microarrays (G4131F, Agilent Technologies, USA) using one color (Cy3) Low Input Quick Amp labeling kit (Agilent Technologies, USA), according to manufacturer instructions. Briefly, total RNA plus spike-in controls were reverse transcribed into double stranded cDNA. The primers used for this reaction contained consecutive thymine bases attached to a T7 promoter that paired at the $5^{\prime}$ end of the first strand of cDNAs. Next, the T7 polymerase was added along with nucleotides labeled with fluorescent cyanine-3 (Cy3) dye, which amplified the antisense complementary RNAs (cRNA). Hybridizations were performed for $17 \mathrm{~h}$ at $65^{\circ} \mathrm{C}$ using an automated system (SureHyb, GE Healthcare, UK). Subsequently, the slides were washed with wash buffer solutions 1 and 2. The solutions Agilent's Stabilization and Drying also were used to protect cyanine probes against ozone degradation. The hybridization signals were captured using the GenePix $4000 \mathrm{~B}$ scanner (Molecular Devices, USA).

\subsection{Microarray data analysis}

Data quantification and quality control were performed using Feature Extraction (FE) software version 15.5 (Agilent Technologies, USA). Expression data were loaded into R-environment (http://www.rproject.org) v.3.1.0 for the further steps. The background adjustment was performed by subtracting median background values from the median expression values. Data were $\log _{2}$ transformed and normalized using quantile function from LIMMA (Linear Models for Microarray Analysis) package (Ritchie et al., 2015). Afterward, an unspecific filter was applied to select the probes with the intensity at least $10 \%$ higher than the negative controls value. Additionally, the positive and negative controls were excluded from the posterior analyses and the replicated probes were averaged. Finally, there were selected only the probes related to a valid Entrez Gene ID. Differentially expressed genes were identified by using Empirical Bayes moderated t-statistics, and the genes were considered statistically significant with False Discovery Rate (FDR) $<0.01$ and fold change $>3.0$ in the contrast analyzed (DEN/ TAA $v s$. untreated). Subsequently, the clusters of co-regulated genes were submitted to functional analysis using the Database for Annotation, Visualization, and Integrated Discovery (DAVID) using the package RDAVID WebService (Fresno and Fernández, 2013). Biological processes with $\mathrm{p}<0.05$ were considered statistically significant in each cluster. The microarray data discussed in this publication have been deposited in NCBI's Gene Expression Omnibus through GEO Series accession number GSE97083 (Edgar et al., 2002).

\subsection{Oxidative stress analysis}

Frozen liver samples $\left(-80^{\circ} \mathrm{C}\right)$ were homogenized in $50 \mathrm{mM}$ phosphate buffer ( $\mathrm{pH}$ 7.4) using a motor-driven Teflon glass Potter Elvehjem $(100 \times \mathrm{g} / \mathrm{min})$ and centrifuged $\left(12000 \times \mathrm{g},-4{ }^{\circ} \mathrm{C}, 15 \mathrm{~min}\right)$. The supernatant was used to determine total protein, catalase, glutathione peroxidase (GSH-Px), glutathione-S-transferase (GST) activities and lipid hydroperoxide levels. Catalase activity was determined in sodium and potassium phosphate buffer containing $10 \mathrm{mM}$ hydrogen peroxide (Bergmeyer, 1974). GSH-Px activity was assayed by following the oxidation of $0.16 \mathrm{mM}$ NADPH in the presence of glutathione reductase which catalyzed the reduction of GSSG formed by the GSH-Px (Nakamura et al., 1974). GST activity was measured in buffer sodium phosphate $(0.1 \mathrm{M}, \mathrm{pH} 7.4)$ containing $1.0 \mathrm{mM}$ of reduced glutathione and $1.0 \mathrm{mM}$ of 1-chloro-2,4 dinitrobenzene (CDNB) as a substrate (Habig et al., 1974). The lipid hydroperoxide levels were measured through hydroperoxide-mediated oxidation of $\mathrm{Fe}^{2+}$, with $100 \mu \mathrm{L}$ of sample and $900 \mu \mathrm{L}$ of a reaction mixture containing $250 \mu \mathrm{M} \mathrm{FeSO}{ }_{4}$, $25 \mathrm{mM} \mathrm{H}_{2} \mathrm{SO}_{4}, 100 \mu \mathrm{M}$ xylenol orange and $4 \mathrm{mM}$ butylated hydroxytoluene in $90 \%(\mathrm{v} / \mathrm{v})$ methanol (Jiang et al., 1991). Lastly, blood samples were collected and serum alanine aminotransferase (ALT) and aspartate aminotransferase (AST) activities in order to monitor hepatotoxicity (Ozer et al., 2008). Both were enzymatically measured by following the rate of oxidation of NADH during the reaction which is proportional to ALT and AST activities (Liquiform - Labtest Diagnóstica, Brazil). All determinations were performed using a microplate reader $\left(25^{\circ} \mathrm{C}\right.$ ) ( $\mu$ Quant-Gen5 2.0 software, Bio-Tec Instruments, USA).

\subsection{Statistical analysis}

The statistical analysis of microarray data was described above. All other data were analyzed by Student $t$-test or Mann-Whitney test. The incidence of histopathological findings was analyzed by Fisher's Exact Test. Significant differences were assumed at $p<0.05$. All statistical analyses were performed using 3.5 Jandel Sigma Stat software (Jandel Corporation, USA). 


\section{Results}

\subsection{General findings}

The DEN/TAA administration led to a marked reduction in body weight throughout the experimental period (Supplementary data 2). In fact, DEN/TAA-treated animals showed reduced final body weight and body weight gain when compared to the untreated rats $(\mathrm{p}<0.001$, for both) (Fig. 1). In addition, these changes were accompanied by a reduction in food intake (data not shown). Previously, chronic administration of TAA has demonstrated to exert systemic toxicity in rats (Furtado et al., 2012; Wallace et al., 2015).

\subsection{Macroscopical, histological findings and ALT/AST}

At necropsy, the livers from DEN/TAA-treated animals showed a clear cirrhotic aspect, presenting rough surfaces with numerous nodules, whereas those from untreated animals showed regular and smooth surfaces (Fig. 1). As expected, DEN/TAA-treatment increased both absolute and relative liver weights ( $\mathrm{p}<0.001$, for both) (Fig. 1).

Both HE and Sirius red-stained liver sections confirmed the development of cirrhosis in all DEN/TAA-treated animals, characterized by several micro and macronodules surrounded and separated by fibrous septa, while untreated animals showed typical liver parenchyma (Figs. 1 and 2). As expected, the clear cirrhotic aspect led to an increase in both serum transaminases levels in DEN/TAA-treated animals ( $\mathrm{p}<0.05$, for both) (Fig. 1). In agreement with the HE-stained sections, the analysis of Sirius red stained sections revealed that DEN/TAA treatment led to a $\sim 4$-fold increase in collagen fraction (\%) compared to the untreated group ( $\mathrm{p}<0.001$ ) (Fig. 2).

The expression of GST-P is considered a classic and reliable biomarker for the identification and quantification of preneoplastic foci and nodules in the rat liver (Tsuda et al., 2003). Most of the described nodules showed to be positive for GST-P (Fig. 2) lesions, presenting a mean number of $\sim 129$ nodules $/ \mathrm{cm}^{2}$ (Fig. 1). The majority of the GST-P positive nodules comprised $<0.20 \mathrm{~mm}^{2}$ and $0.20-0.30 \mathrm{~mm}^{2}$ size classes (Fig. 2). These lesions can be also considered hyperplastic lesions since Ki-67 labeling was markedly increased ( $\sim 15$-fold) ( $\mathrm{p}<0.001$ ) (Figs. 2). Lastly, the DEN/TAA led to the development of a few neoplastic lesions, including hepatocellular adenomas, HCCs and cholangiocarcinomas (CCAs) $(30 \%, 10 \%$ and $10 \%$ of DEN/TAA-treated animals, respectively) (Fig. 3).

\subsection{Global gene expression}

In order to elucidate the molecular events related to cirrhosis-associated hepatocarcinogenesis model in rats, global gene expression analysis was performed in nodule-filled liver tissue. The DEN/TAAtreated animals presented 359 differentially expressed genes compared to the untreated animals (158 up- and 201 down-regulated genes) (Supplementary data 3). The information (gene symbol, name and fold change) of the main up and downregulated genes presented next are also highlighted in Table 1.

\subsubsection{Upregulated genes}

The DAVID functional analysis with enriched Gene Ontology (GO) terms revealed that $\sim 80 \%$ of the upregulated genes were related to extracellular matrix organization, response to oxidative stress or immune function (Table 2, Fig. 4), biological processes directly linked to the cirrhotic process. Pro-inflammatory genes, such as Lsp1, Ctse, $C c l 21 b, C 1 q a, C 1 q b$, and Ccl21b, were up-regulated in the cirrhotic livers (Tables 1 and 2). Particularly, we found that procollagen type I genes (Col1 $\alpha 1$ and Col1 $\alpha 2)$ were significantly upregulated in DEN/TAAtreated animals (Tables 1 and 2), corroborating with the increase in collagen content (\%) by the analysis of Sirius red-stained liver sections. Notably, annexin A2, decorin and galectin-3 binding protein genes (Anxa 2, Dcn and Lgals3 bp, respectively), regulators of collagen synthesis or extracellular matrix assembly, were also upregulated in cirrhotic livers (Tables 1 and 2). Notably, Anxa 2 is also related to cancer cell invasion and tumorigenic potential (Zhang et al., 2013).

Additionally, genes of tissue inhibitor of metalloproteinases 1 and 2 (Timp1 and Timp2), negative regulators of collagen degradation, were upregulated in those animals (Tables 1 and 2). Lastly, we found that glutathione S-transferase placental form genes 1 and 2 were strikingly
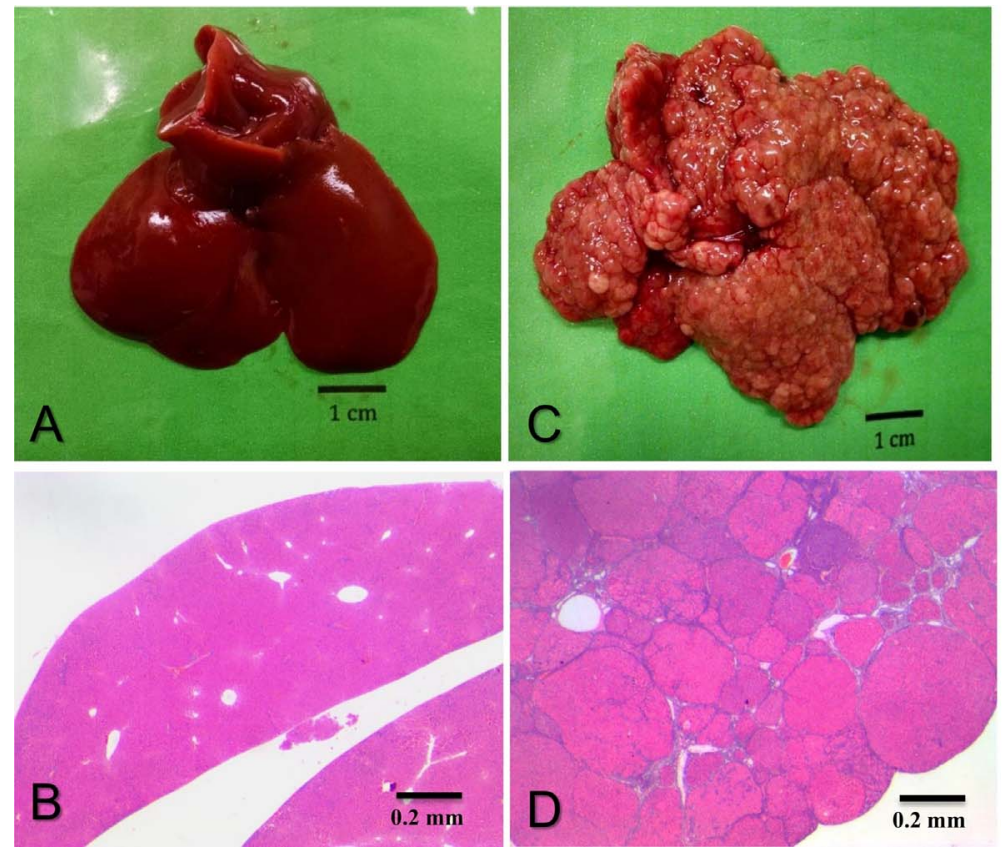

E

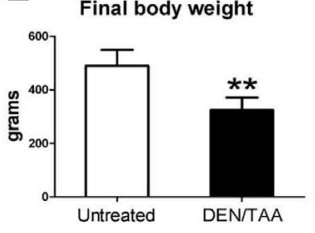

G
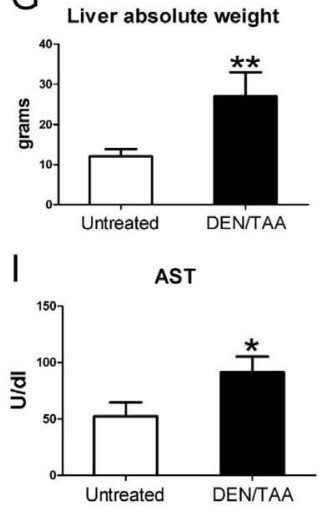

F

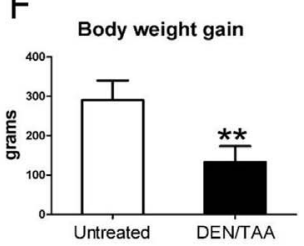

$\mathrm{H}$ Liver relative weight

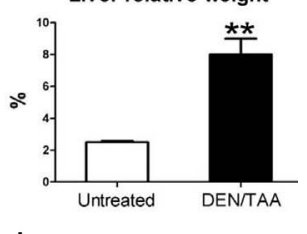

$J$

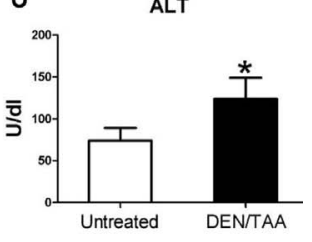

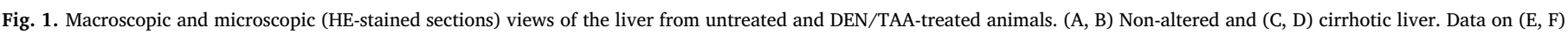

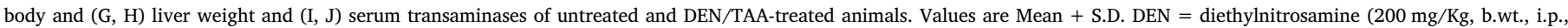

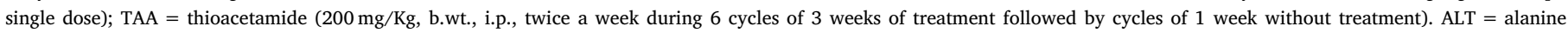
aminotransferase, AST $=$ aspartate aminotransferase. *,** Statistical difference compared to untreated group by Student $t$-test, $\mathrm{p}<0.05$ and $\mathrm{p}<0.001$, respectively. 


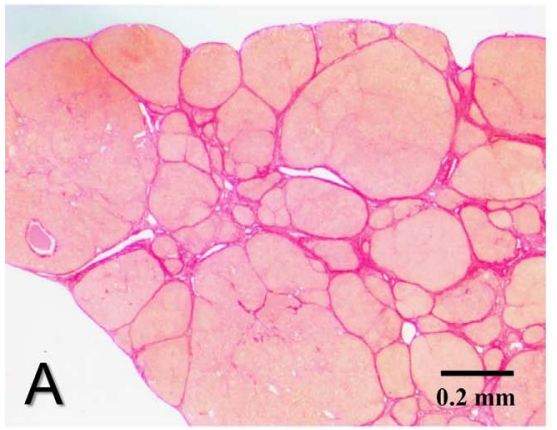

Collagen

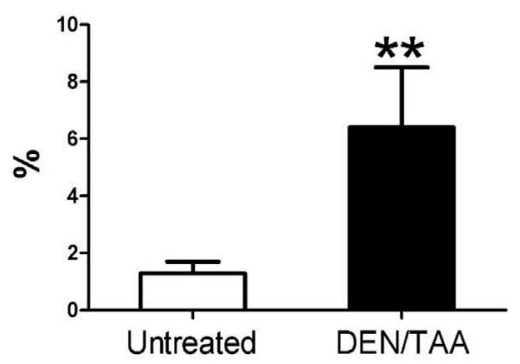

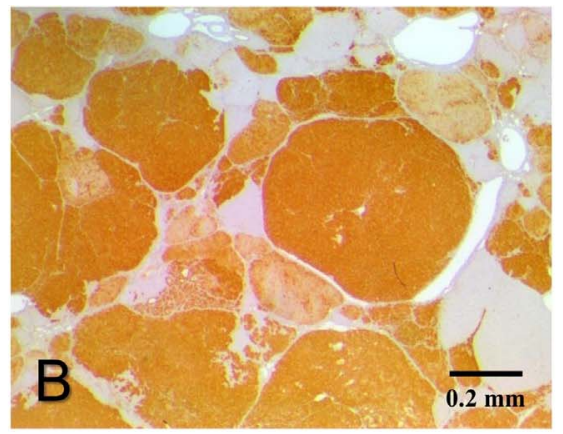

GST-P analysis

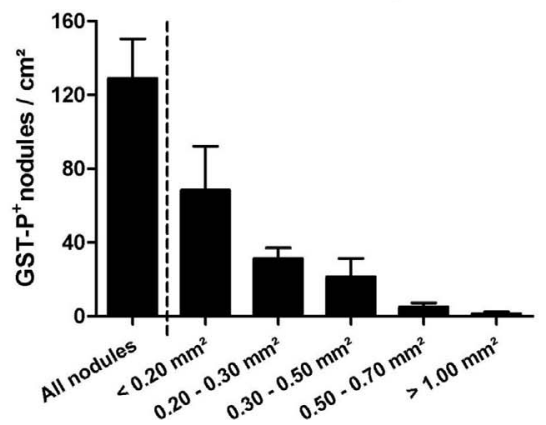

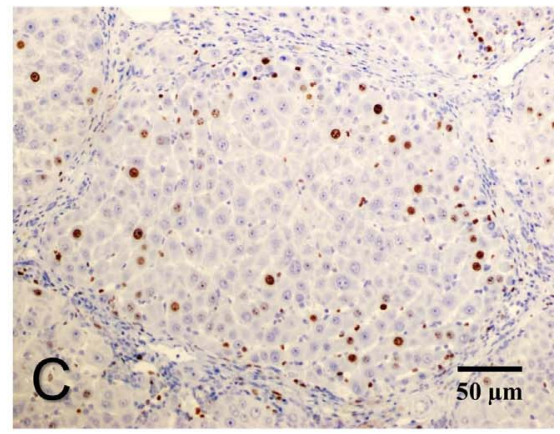

Ki-67 labeling

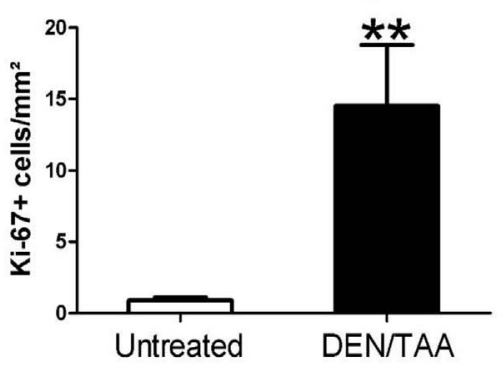

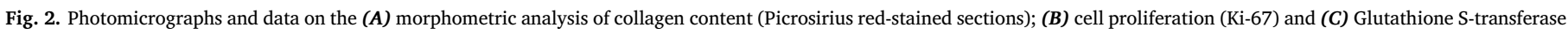

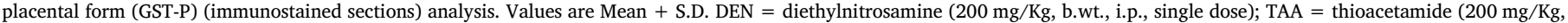

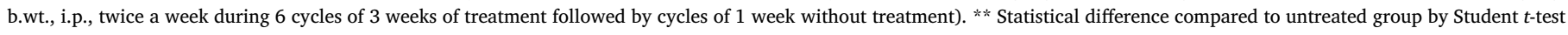
(p $<0.001)$.

upregulated in the liver of DEN/TAA-treated animals (118 and 63 fold up, respectively) (Table 1), corroborating with GST-P immunostaining findings in this group.

\subsubsection{Downregulated genes}

Functional analysis also showed that the main biological functions related to the downregulated genes were metabolic processes, response to stimulus, stress or antioxidant processes, corresponding to $71 \%$ of these genes (Table 3, Fig. 4). Among these biological processes, we highlight glutathione peroxidase 1, glutathione S-transferase mu type 3 and catalase genes (Gpx1, Gstm3, and Cat, respectively), that encode important antioxidant enzymes, showed to be downregulated in DEN/ TAA regimen (Tables 1 and 3).

\subsection{Oxidative stress analysis}

In TAA-induced fibrosis/cirrhosis models, the enhanced oxidative stress is preceded by TAA bioactivation. This thiono-sulfur-containing compound undergoes oxidation by a mixed-function oxidase system, particularly by CYP 2E1 and FAD-containing monooxygenase (FMO), generating reactive oxygen species (ROS) and the also chemically-reactive thioacetamide-S-oxide (TASO) and thioacetamide-S,S-dioxide $\left(\mathrm{TASO}_{2}\right)$ metabolites (Kang et al., 2008; Staňková et al., 2010). These reactive compounds exert oxidative damage to proteins, lipids, and nucleic acids, and ultimately lead to hepatocyte death, manifested as classical centrilobular necrosis (Wallace et al., 2015). Since the oxidative stress is believed to be a major participating factor in TAA-induced liver injury, we measured lipid hydroperoxide levels in the liver. Indeed, a significant increase in lipid hydroperoxide was observed in the DEN/TAA group ( $\mathrm{p}<0.05$ ) (Fig. 5).

The GST, GSH-Px, and catalase are important liver antioxidant enzymes involved in protective mechanisms against endogenous and exogenous substances and ROS-mediated damage in the liver as well as in other tissues (Townsend and Tew, 2003; Chelikani et al., 2004; Brigelius-Flohé and Maiorino, 2013). Considering that it was observed a downregulation in many antioxidant enzyme genes, we measured the activity of these enzymes. In agreement with the gene expression, DEN/ TAA regimen significantly decreased the activity of total GSH-Px, total GST and catalase enzymes ( $\mathrm{p}<0.05$, for all) compared to the untreated animals (Fig. 5).

\subsection{Densitometric analysis of MMP-2 and 9 forms}

The matrix metalloproteinases (MMPs), as the gelatinases MMP-2 and 9, are collagenases involved in ECM remodeling in both physiological and pathological processes, including liver cirrhosis (Klein and Bischoff, 2011). The DEN/TAA regimen increased the activity of intermediate and active forms of MMP-2 and the activity of pro and active MMP-9 ( $p<0.001$, for all) compared to the untreated animals (Fig. 5).

\section{Discussion}

In the present study, we characterized the histological, biochemical and molecular aspects involved in a cirrhosis-associated hepatocarcinogenesis rat model. Global gene expression profile showed upregulated genes involved in extracellular matrix deposition (Col1 $\alpha 1$ and Col1 2 , Timp1 and Timp2). In agreement with these findings, animals presented extensive liver cirrhosis with increased and collagen deposition. Moreover, the activity of MMPs 2 and 9 was enhanced. Interestingly, Gstp1 and 2 genes were markedly upregulated, in keeping with the development of several GST-P-positive preneoplastic foci and hyperplastic nodules. In contrast, both gene expression and activity of important antioxidant enzymes were decreased (GSH-Px, GST, and catalase). Our study provides additional information on key pathways involved in the rat cirrhotic-associated hepatocarcinogenesis, which were very similar to the corresponding human liver disease (Table 4).

The DEN/TAA treatment using periodical cycles of TAA administration led to an increase in hepatic lipid hydroperoxide levels, a suitable indicator of oxidative stress in TAA-induced models (Sun et al., 

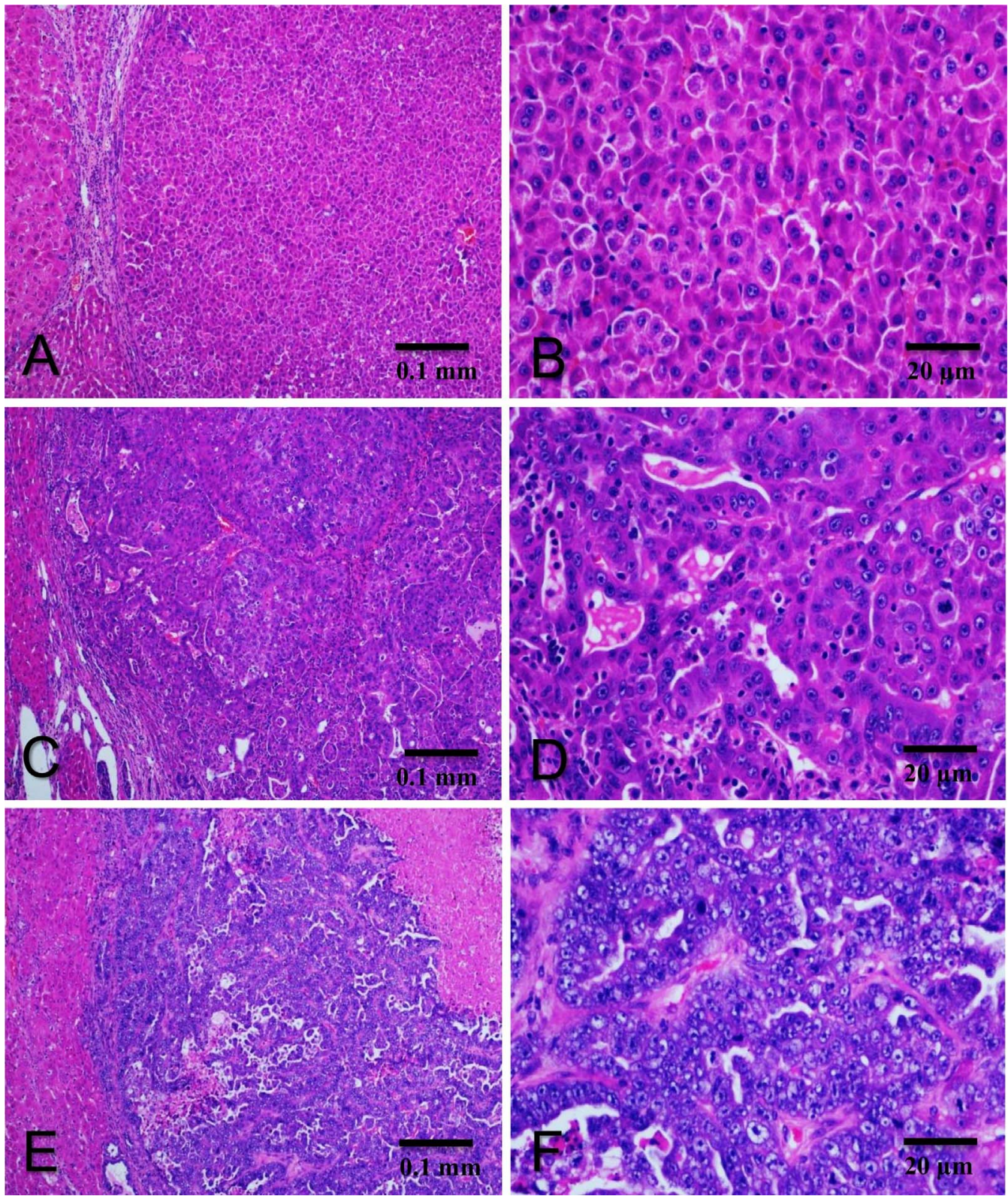

Fig. 3. Photomicrographs of the main hepatocellular lesions observed in DEN/TAAtreated animals (HE-stained sections). (A-B) Hepatocellular adenoma; (C-D) Hepatocellular carcinoma showing trabecular aspect; $(\boldsymbol{E}-\boldsymbol{F})$ Cholangiocarcinoma.
2000). Interestingly, enhanced lipid peroxidation is a common feature in human chronic liver disease (Table 4), including cirrhosis itself and other risk conditions for HCC development, such as nonalcoholic fatty liver disease (NAFLD) and chronic hepatitis C (Pratico et al., 1998; Konishi et al., 2006). The reactive compounds generated by TAA bioactivation exert oxidative damage to proteins, lipids, and nucleic acids, and ultimately lead to hepatocyte death, manifested as classical centrilobular necrosis (Wallace et al., 2015). Thus, the alterations in the liver microenvironment caused by TAA repeated administration partially mimics chronic injury in human liver diseases.

Experimental evidence indicates that both oxidative stress and hepatocyte death are the necessary stimuli to the recruitment of inflammatory cells and activation of collagen-producing cells, mainly HSCs (Zhou, 2014). In fact, various pro-inflammatory genes were upregulated in the cirrhotic livers, such as Lsp1, Ctse, Ccl21b, C1qa, C1qb, and Ccl21b. The lymphocyte-specific 1 (Lsp1) gene encodes a binding protein expressed in many immune cells that promotes neutrophil transendothelial migration (Liu et al., 2005). Additionally, the CCL21 cytokine encoded by (C-C motif) ligand $21 \mathrm{~b}(\mathrm{Ccl} 21 \mathrm{~b})$ gene also stimulates the migration of dendritic cells and HSC and the coactivation of
$\mathrm{T}$ cells, key members of hepatic pro-fibrogenic response (Bonacchi et al., 2003; Marsland et al., 2005; Gollmer et al., 2009). Notably, the expression of this gene showed to be up-regulated in the liver of patients with chronic hepatitis C (Bonacchi et al., 2003). The C1qa and $C 1 q b$ genes encode the alpha and beta polypeptide chains of serum complement subcomponent C1q, respectively. Generally, it is observed an increased activity of the complement system in the serum and/or liver of patients with alcoholic hepatitis and chronic hepatitis $\mathrm{C}$ (Shen et al., 2014; Vasel et al., 2014). Moreover, C1qb protein expression shown to be increased in activated HSCs from the liver of $\mathrm{CCl}_{4}$-treated rats ( $\mathrm{Ji}$ et al., 2012). Ultimately, the cathepsin E (Ctse) gene, which encodes an aspartate peptidase, was also up-regulated in DEN/TAA model. Previously, other members of cathepsin family (cathepsins B and cathepsin D) were found to induce in vitro HSC activation and proliferation (both mouse and human LX2 cells) (Moles et al., 2009). In addition, cathepsin B inhibition led to the attenuation of chemicallyinduced fibrogenesis in male mice (Moles et al., 2009). Thus, the upregulation of these genes in DEN/TAA model may have contributed to immune response activation, and ultimately, to increase the collagen deposition in the liver parenchyma. 
Table 1

The main up and downregulated genes observed in the liver DEN/TAA-treated animals, considering fold change $>3.0^{*}$.

\begin{tabular}{|c|c|c|c|}
\hline ProbeID & Gene symbol & Gene name & Fold change \\
\hline \multicolumn{4}{|l|}{ Upregulated } \\
\hline A_44_P238421 & Col1 $\alpha 1$ & procollagen, type 1 , alpha 1 & 3,863513835 \\
\hline A_43_P12783 & Col1 $\alpha 2$ & procollagen, type I, alpha 2 & 5,314160908 \\
\hline A_42_P532103 & Anxa2 & annexin A2 & 12,14998439 \\
\hline A_42_P647599 & Den & decorin & 3,461439241 \\
\hline A_44_P1042473 & Lgals3bp & $\begin{array}{l}\text { lectin, galactoside-binding, } \\
\text { soluble, } 3 \text { binding protein }\end{array}$ & 4,574076853 \\
\hline A_44_P461154 & Timp1 & $\begin{array}{l}\text { tissue inhibitor of } \\
\text { metalloproteinase } 1\end{array}$ & 5,87052891 \\
\hline A_44_P1017481 & Timp2 & $\begin{array}{l}\text { tissue inhibitor of } \\
\text { metalloproteinase } 2\end{array}$ & 3,024160583 \\
\hline A_44_P182221 & Gstp1 & $\begin{array}{l}\text { glutathione-S-transferase, pi } \\
1\end{array}$ & 118,3077032 \\
\hline A_43_P13342 & Gstp2 & glutathione S-transferase, pi 2 & 63,33706647 \\
\hline A_42_P621642 & Lsp1 & lymphocyte specific 1 & 3,341314921 \\
\hline A_44_P178252 & $C c l 21 b$ & $\begin{array}{l}\text { chemokine ( } \mathrm{C}-\mathrm{C} \text { motif) } \\
\text { ligand } 21 \mathrm{~b} \text { (serine) }\end{array}$ & 5,623005865 \\
\hline A_44_P487764 & C1qa & $\begin{array}{l}\text { complement component } 1, \mathrm{q} \\
\text { subcomponent, alpha } \\
\text { polypeptide }\end{array}$ & 3,032245333 \\
\hline A_42_P781919 & $C 1 q b$ & $\begin{array}{l}\text { complement component } 1, \mathrm{q} \\
\text { subcomponent, beta } \\
\text { polypeptide }\end{array}$ & 3,105587498 \\
\hline A_42_P801679 & Ctse & cathepsin $\mathrm{E}$ & 5,578321899 \\
\hline \multicolumn{4}{|l|}{ Downregulated } \\
\hline A_44_P123315 & Gpx1 & glutathione peroxidase 1 & $-3,944715755$ \\
\hline A_44_P362954 & Cat & Catalase & $-3,698045218$ \\
\hline A_42_P716352 & Gstm3 & $\begin{array}{l}\text { glutathione S-transferase, mu } \\
\text { type } 3\end{array}$ & $-6,611173656$ \\
\hline
\end{tabular}

* For the general list of differentially expressed genes see Supplementary data 2.

The type I collagen is a product of two different genes, Col1 $\alpha 1$ and Col1 $\alpha 2$, whose expression is generally coordinated (Gelse et al., 2003). The collagen type I triple helix is usually formed as a heterotrimer by two identical $\alpha 1$ (I)-chains (encoded by Col1 $\alpha 1$ ), and one $\alpha 2(\mathrm{I})$-chain (encoded by Col1 $\alpha 2$ ) (Gelse et al., 2003). This molecule is the predominant ECM protein in cirrhosis, increasing $\sim 15 \%$ in cirrhotic compared to normal human liver (Aycock and Seyer, 1989). In our model, the results suggest that the increase in collagen fibers fraction (\%), as well as the substitution of a normal for a nodule-filled liver parenchyma in DEN/TAA-treated group, resulted primarily from increased transcription of both type I collagen genes.

Under physiological conditions, the ECM remodeling is a process that involves the cleavage of ECM components, being is essential for maintaining a suitable liver architecture, homeostasis, and microenvironment (Bonnans et al., 2014). The major proteinases involved in ECM degradation are the MMPs (Klein and Bischoff, 2011). In the proposed model of cirrhosis-associated hepatocarcinogenesis, we
A

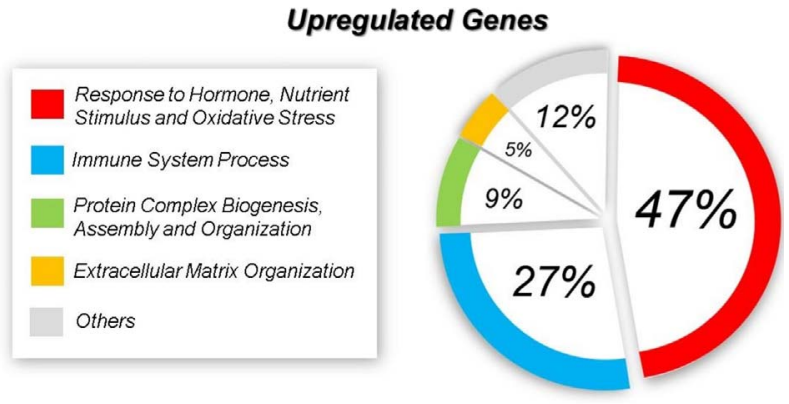

B

Downregulated Genes
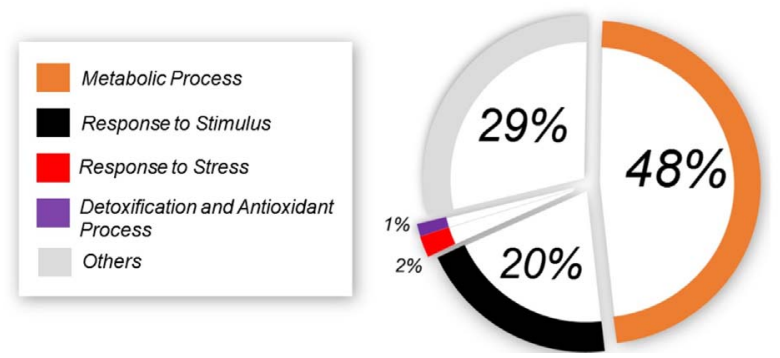

Fig. 4. Biological Functions of $(\boldsymbol{A})$ up and $(\boldsymbol{B})$ down-regulated genes in the liver from DEN/TAA animals in comparison to the untreated animals according to DAVID functional analysis with enriched Gene Ontology (GO) terms.

observed increased activity of active forms of both MMP-2 and 9 when compared to normal liver. Some of these results are in keeping with human cirrhosis (Table 4), in view that active MMP-2 is detectable in cirrhotic but not in normal liver samples (Préaux et al., 1999). The MMP-2 and 9 proenzymes can be activated by forming a complex with TIMP-2 and by oxidative stress and cytokines, respectively (Maeda et al., 1998; Bernardo and Fridman, 2003; Han et al., 2007). Both MMP2 and 9 are directly linked to the proteolytic degradation of basement membrane components, including type IV collagen (Klein and Bischoff, 2011). An imbalance in MMP activity, as observed here, could lead to aberrant ECM remodeling and contribute to the loss of typical liver architecture and homeostasis, classical hallmarks of liver cirrhosis. Moreover, the MMP-mediated cleavage of ECM components leads to the release of proinflammatory cytokines, as IL-1ß (Schönbeck et al., 1998). Interestingly, previous studies suggested that MMP-9-mediated degradation of ECM and MMP-2 synthesis were responsible for HSC activation and proliferation in vitro, respectively (Benyon et al., 1999; Han et al., 2007). Our findings indicate that MMP activation may have contributed to ECM remodeling, ultimately increasing collagen deposition and leading to cirrhosis.

In normal liver, the activity of many collagenases is negatively modulated by the tissue inhibitors of metalloproteinases (TIMPs),

Table 2

Upregulated genes and biological functions present in the enriched Gene Ontology (GO) biological processes modulated in DEN/TAA-treated compared to untreated animals.

\begin{tabular}{|c|c|c|}
\hline Biological functions & GOs & Genes \\
\hline \multicolumn{3}{|l|}{ Upregulated } \\
\hline $\begin{array}{l}\text { Response to Hormone, Nutrient } \\
\text { Stimulus and Oxidative Stress }\end{array}$ & $\begin{array}{l}\text { GO:0010033, GO:0048545, GO:0010035, GO:0009719, GO:0009725, } \\
\text { GO:0031960, GO:0051384, GO:0009628, GO:0007584, GO:0043627, } \\
\text { GO:0006979, GO:0042542, GO:0000302 }\end{array}$ & $\begin{array}{l}\text { A2m, Acp5, Aldh1a1, Aldh3a1, Aldoa, Anxa1, Anxa5, Anxa7, C1qb, } \\
\text { Col1a1, Coro1a, Cryab, Cygb, Dcn, Dmbt1, Ephx1, Gclc, Glul, Gstm1, } \\
\text { Hmgcr, Mgp, Nqo1, Sparc, Timp1, Timp2, Txnrd1 }\end{array}$ \\
\hline Immune System Process & $\begin{array}{l}\text { GO:0002250, GO:0002443, GO:0002449, GO:0002460, GO:0002478, } \\
\text { GO:0002495, GO:0002504, GO:0006952, GO:0006955, GO:0016064, } \\
\text { GO:0019724, GO:0019882, GO:0019884, GO:0019886, GO:0045087, } \\
\text { GO:0048002 }\end{array}$ & $\begin{array}{l}\text { A2m, Acp5, C1qa, C1qb, Ccl21b, Cd74, Ctse, Cyba, Defb1, Gbp2, Lsp1, } \\
\text { Rt1-Da, Rt1-Db1 }\end{array}$ \\
\hline $\begin{array}{l}\text { Protein Complex Biogenesis, } \\
\quad \text { Assembly and Organization }\end{array}$ & $\begin{array}{l}\text { GO:0006461, GO:0007017, GO:0007018, GO:0034621, GO:0034622, } \\
\text { GO:0043933, GO:0051258, GO:0051259, GO:0051260, GO:0065003, } \\
\text { GO:0070271 }\end{array}$ & $\begin{array}{l}\text { Aldh1a1, Anxa5, Atpif1, Cd74, Cryab, Cyba, Glul, Kif12, Loc300303, } \\
\text { Mgp, Nap1l1, Npm1, Tubb2c, Tubb5, Tubb6 }\end{array}$ \\
\hline Extracellular Matrix Organization & GO:0030198, GO:0030199, GO:0043062 & Anxa2, Col1 $\alpha 1$, Col1 $\alpha 2$, Dcn, Lgals3 \\
\hline
\end{tabular}


Table 3

Downregulated genes and biological functions present in the enriched Gene Ontology (GO) biological processes modulated in DEN/TAA-treated compared to untreated animals.

\begin{tabular}{|c|c|c|}
\hline Biological functions & GOs & Genes \\
\hline \multicolumn{3}{|l|}{ Downregulated } \\
\hline Metabolic Process & $\begin{array}{l}\text { GO:0000096, GO:0000097, GO:0005976, GO:0005977, GO:0005996, } \\
\text { GO:0006006, GO:0006073, GO:0006091, GO:0006109, GO:0006112, } \\
\text { GO:0006534, GO:0006575, GO:0006638, GO:0006639, GO:0006641, } \\
\text { GO:0006644, GO:0006662, GO:0006790, GO:0006869, GO:0008202, } \\
\text { GO:0008652, GO:0009062, GO:0009063, GO:0009069, GO:0009070, } \\
\text { GO:0009116, GO:0009119, GO:0009309, GO:0009310, GO:0009894, } \\
\text { GO:0009896, GO:0010565, GO:0010675, GO:0010676, GO:0010872, } \\
\text { GO:0010873, GO:0010876, GO:0010906, GO:0010907, GO:0015980, } \\
\text { GO:0016042, GO:0016053, GO:0016054, GO:0018904, GO:0019216, } \\
\text { GO:0019217, GO:0019218, GO:0019318, GO:0019637, GO:0031329, } \\
\text { GO:0031331, GO:0032368, GO:0032881, GO:0033500, GO:0034637, } \\
\text { GO:0042278, GO:0042304, GO:0042593, GO:0042632, GO:0043467, } \\
\text { GO:0043470, GO:0043471, GO:0044042, GO:0044242, GO:0044264, } \\
\text { GO:0044271, GO:0044272, GO:0045723, GO:0045834, GO:0045913, } \\
\text { GO:0045923, GO:0045940, GO:0046128, GO:0046394, GO:0046395, } \\
\text { GO:0046486, GO:0046498, GO:0046500, GO:0046889, GO:004689, } \\
\text { GO:0050994, GO:0050996, GO:0055092 }\end{array}$ & $\begin{array}{l}\text { Acaca, Acox2, Acsl1, Acsl5, Adra1b, Agt, Agxt, Amacr, Apoa2, Apoa4, } \\
\text { Apom, Avpr1a, Baat, Bhmt, Cat, Cbs, Cdo1, Crot, Cth, Cyp1a2, Dcxr, Ebp, } \\
\text { Ehhadh, Faah, Fabp1, Fads1, Fasn, G6pc, Gamt, Gck, Gckr, Gne, Gnmt, } \\
\text { Gpld1, Gpx1, Gulo, Hal, Hmgcs2, Hpd, Hsd3b, Igf1, Insig2, Itih3, Khk, } \\
\text { Kynu, Lipc, Scd1, Mat1a, Onecut1, Pck1, Pemt, Pfkfb1, Pklr, Prodh2, } \\
\text { Slc27a5, Slc37a4, Srd5a1, Sult2a1, Upb1 }\end{array}$ \\
\hline Response to Stimulus & $\begin{array}{l}\text { GO:0001101, GO:0007584, GO:0009719, GO:0009725, GO:0009743, } \\
\text { GO:0009744, GO:0009746, GO:0009749, GO:0009991, GO:0010033, } \\
\text { GO:0010243, GO:0014075, GO:0031667, GO:0031960, GO:0032868, } \\
\text { GO:0034284, GO:0034285, GO:0043200, GO:0043434, GO:0048545, } \\
\text { GO:0051384, GO:0051591 }\end{array}$ & $\begin{array}{l}\text { Abcb11, Acaca, Acsl1, Acsl5, Adra1b, Agxt, Ak3l1, Apoa2, Apoa4, Apom, } \\
\text { Avpr1a, Cbs, Cdo1, Crot, Cxcl12, Cyp1a2, Cyp2c23, Cyp2c7, Egfr, Fads1, } \\
\text { G6pc, Gck, Gpx1, Gstm3, Hmgcs2, Igf1, Insig2, Khk, Kynu, Lipc, Pck1, } \\
\text { Pemt, Pfkfb1, Pklr, Sdc2, Serpina3m, Serpinc1, Slc37a4 }\end{array}$ \\
\hline Response to Stress & $\begin{array}{l}\text { GO:0006800, GO:0010035, GO:0034599, GO:0034614, GO:0042743, } \\
\text { GO:0042744, GO:0070301 }\end{array}$ & Apoa4, Avpr1a, Cat, Cyp1a2, Egfr, Gpx1, Khk, Lipc, Pklr \\
\hline $\begin{array}{l}\text { Detoxification and } \\
\text { Antioxidant Process }\end{array}$ & GO:0006805, GO:0009410, GO:0042537 & Acsl1, Cyp1a2, Cyp2c, Cyp2e1, Gpx1, Gstm3, Купu \\
\hline
\end{tabular}

including TIMP-1 and TIMP-2 (Ra and Parks, 2007). Here, we found that tissue inhibitors of metalloproteinases 1 and 2 (Timp1 and Timp2) genes were overexpressed in DEN/TAA regimen as well. Experimental data already demonstrated that Timp1 overexpression in transgenic mice impaired the clearance of ECM led to the extensive accumulation of it and promoted chemically-induced liver fibrosis in mice (Yoshiji et al., 2000). Furthermore, the siRNA-mediated silencing of TIMP-1 led to significantly reduced HSC proliferation in vitro (Fowell et al., 2011). It is also reasonable to point that both TIMP1 and 2 mRNA expressions were detected in the liver of cirrhotic patients but not in healthy ones (Table 4) (Nie et al., 2002). Thus, along with Col1 $\alpha 1$ and Col1 2 up- regulation, the over-expression of Timp1 and Timp2 genes, reinforces the anabolic status of type I collagen synthesis and contributes to cirrhosis development in DEN/TAA-treated rats.

Besides the collagen fibril directly-related genes, we observed that many "fibrogenesis hallmark genes" were upregulated in the liver from the DEN/TAA regimen, as Lgals $3 b p$, Anxa2, and Dcn. The galectin-3, a $\beta$-galactoside-binding animal lectin encoded by Lgals3 bp gene, regulates cell-ECM interactions and its importance in fibrogenesis was highlighted by Henderson et al. (2006) since galectin 3 inhibition showed to attenuate chemically-induced fibrosis in mice by reducing HSC activation. Microarray analysis of human cirrhotic livers also
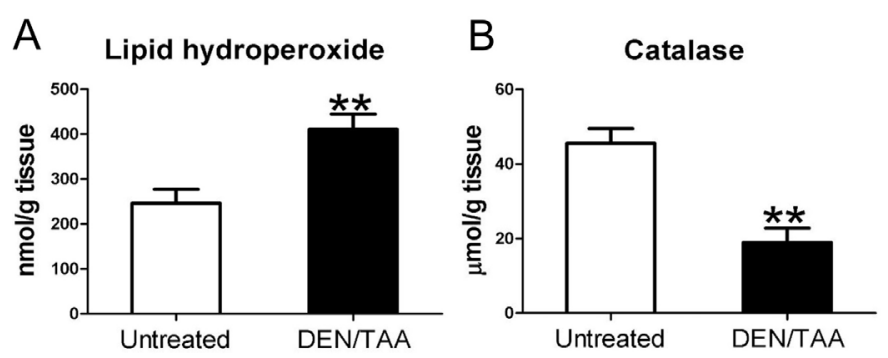

C

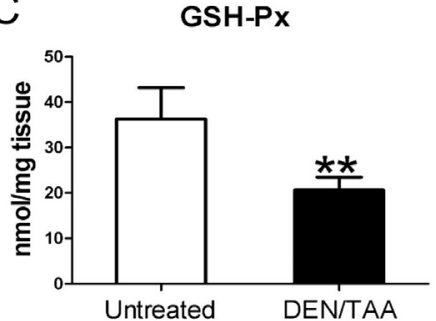

D

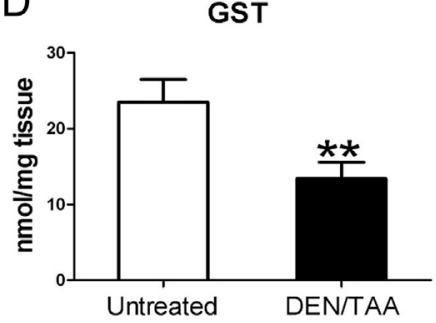

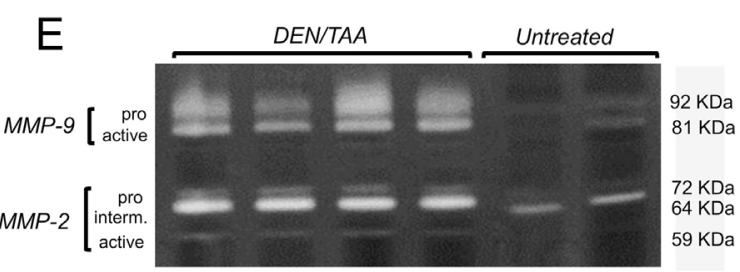

$\mathrm{F}$

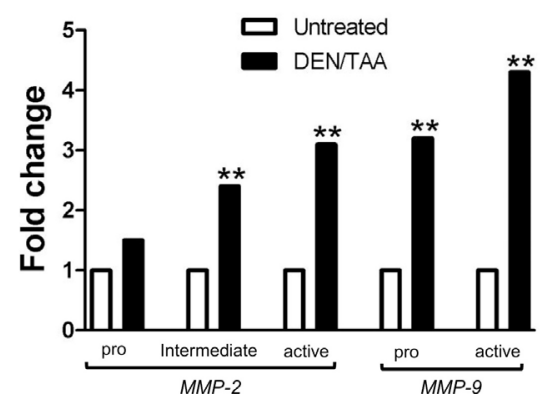

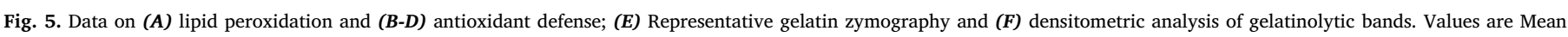

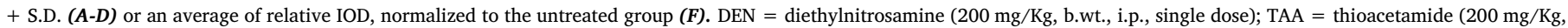

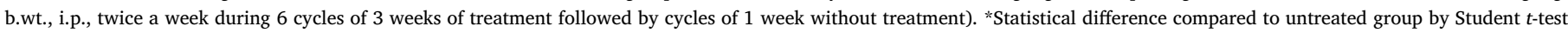
(p < 0.001). 
Table 4

Similarities and differences between DEN/TAA-induced rat cirrhosis-associated hepatocarcinogenesis and the corresponding human liver disease.

\begin{tabular}{llll}
\hline Biological feature & Rat & Human & References \\
\hline Histological & & & \\
Collagen deposition/Nodules & $\uparrow$ & $\uparrow$ & Aycock and Seyer (1989) \\
GST-P immunoexpression & $\uparrow$ & - & \\
Biochemical & & & \\
Oxidative stress & $\uparrow$ & $\uparrow$ & Pratico et al. (1998) \\
& & & Konishi et al. (2006) \\
Antioxidant defense & $\downarrow$ & $\downarrow$ & Czuczejko et al. (2003) \\
& & & Czeczot et al. (2006) \\
& & & Li et al. (2013) \\
Molecular & & & \\
Timp1/TIMP1 mRNA & $\uparrow$ & $\uparrow$ & Nie et al. (2002) \\
Timp2/TIMP2 mRNA & $\uparrow$ & $\uparrow$ & Nie et al. (2002) \\
Lgals3 bp/LGALS3BP mRNA & $\uparrow$ & $\uparrow$ & Chan et al. (2016) \\
Anxa2/ANXA2 mRNA & $\uparrow$ & $\uparrow$ & Mohammad et al. (2008) \\
Active MMP-2 activity & $\uparrow$ & $\uparrow$ & Préaux et al. (1999) \\
\hline
\end{tabular}

$\uparrow$ : increased; $\downarrow$ : decreased; - : not applicable.

showed increased expression of LGALS3BP (Table 4) (Chan et al., 2016). In contrast, both decorin (Dcn) and annexin A2 (Anxa2) are negative regulators of collagen 1 assembly/maturation and gene expression, respectively (Mochida et al., 2009; Schäfer et al., 2015). Here, their enhanced expression may be considered a compensatory response to the increased collagen gene expression and deposition. These features resemble human cirrhosis associated with HCC development since different studies already demonstrated enhanced expression of decorin gene and galectin 3 binding protein in cirrhotic liver and/or HCC tissue (Hsu et al., 1999; Zindy et al., 2005). Therefore, considering that the profibrogenic status is obviously enhanced in our DEN-TAA model, we propose Col1 $\alpha 1$, Col1 $\alpha 2$, Timp1, Timp2 and Lgals3 bp genes as potential molecular targets for the development of novel anti cirrhotic therapies (Fig. 6).

In addition to the clear fibrotic environment in DEN/TAA-treated group, we observed decreases in both gene expression and activity of GSH-Px, GST, and catalase. Catalase, a hydroperoxidase enzyme, prevents ROS formation and oxidative damage by degrading hydrogen peroxide (Chelikani et al., 2004). The GSTs, including GST mu type 3, are a wide family of Phase II detoxification enzymes that catalyze the conjugation of glutathione (GSH), a molecule with potent electron-donating capacity, to a wide variety of electrophilic compounds (Townsend and Tew, 2003). Ultimately, when oxidative damage occurs to cell and organelle membrane lipids, another GSH-dependent enzyme, the GSH-Px, neutralizes the reactive products of this process, the lipid hydroperoxides (Brigelius-Flohé and Maiorino, 2013). Here, the severe TAA-induced oxidative stress, measured by lipid hydroperoxide levels, could have depleted the antioxidant capacity of both catalase and GSHdependent (GSH-Px and GST) axis by decreasing enzyme activity and gene expression in nodule-filled livers. These features are similar to some human studies that also showed decreased activity or levels of GSH-dependent enzymes (including GST and GSH-Px) in HCC tissue, plasma orserum of patients with other chronic liver diseases (Table 4) (Czuczejko et al., 2003; Czeczot et al., 2006; Li et al., 2013).

When the capacity of the liver antioxidant system is impaired, the level of oxidative stress rises, predisposing hepatocytes to DNA oxidative damage and leading to mutations and genomic instability, fundamental traits of the multistep process of carcinogenesis (Hanahan and Weinberg, 2011). Mizukami et al. (2010) showed that the accumulation of lipid hydroperoxide end products in the liver could facilitate the emerging of GST-P positive foci. The GST-P enzyme is highly expressed in normal placental tissue and is almost absent from normal adult hepatocytes (Power et al., 1987; Zusterzeel et al., 1999). The increased expression of this marker in adult liver tissue has been extensively proposed as a suitable biomarker for the identification and quantification of preneoplastic hepatocellular foci and nodules in rats (Tsuda et al., 2003). Although some studies already reported enhanced immunoexpression of GST-P in some cases of human cirrhosis and HCC (Shen et al., 2003; Yusof et al., 2003), this marker is not usually applied for diagnostic purposes in human hepatocarcinogenesis (Table 4).

In the present study, we found a marked overexpression Gstp1 and Gstp2, a high number of GST-P positive nodules and increased cell proliferation in nodule-filled livers. It is well-accepted that the appearance of these liver lesions may be initiated through putative somatic mutations in normal hepatocytes by the action of genotoxic hepatocarcinogens, such as DEN, and promoted by the proliferative stimuli of the TAA-induced fibrotic/cirrhotic liver environment (Ogawa, 2009). Then, the results indicate that chemically-induced liver damage and subsequent impairment of antioxidant response may have predisposed rats to the development of preneoplastic GST-P positive lesions. Furthermore, these hepatocellular preneoplastic lesions have been employed as end-point lesions in short and medium-term bioassays instead of neoplastic lesions, which enables the early screening of potential modifying factors (causative or preventive) of early hepatocarcinogenesis (Tatematsu et al., 1987; Ito et al., 1996). In our model, in light of the clearly impaired antioxidant axis predisposing rats to the development of preneoplastic lesions, the identification of substances or compounds that positively regulates gene expression and/or activity of catalase and GSH-related antioxidant enzymes could be understandably considered as good strategies for the prevention or treatment of cirrhosis-associated hepatocarcinogenesis (Fig. 6).

It is also worthy of note that Anxa2 gene was upregulated in DEN/ TAA-treated rats. The Annexin A2 is positively associated with cancer cell proliferation, migration and tumor growth (Zhang et al., 2013). The increased expression of this gene is frequently observed in human HCC but absent in normal liver tissue (Table 4) (Mohammad et al., 2008). Here, Anxa2 upregulation could have contributed to an increase in cell proliferation and predisposed rats to the development of many hepatocellular preneoplastic and some neoplastic lesions.

In conclusion, we proposed a suitable cirrhosis-associated hepatocarcinogenesis chemically-induced rat model, characterizing its main morphological, biochemical and molecular traits and also featuring its remarkable similarities to the corresponding human liver disease (Table 4). The establishment of this model in further research could provide insights into molecular characteristics of the very early malignant liver disease and be applied to the development of potential preventive and therapeutic strategies.

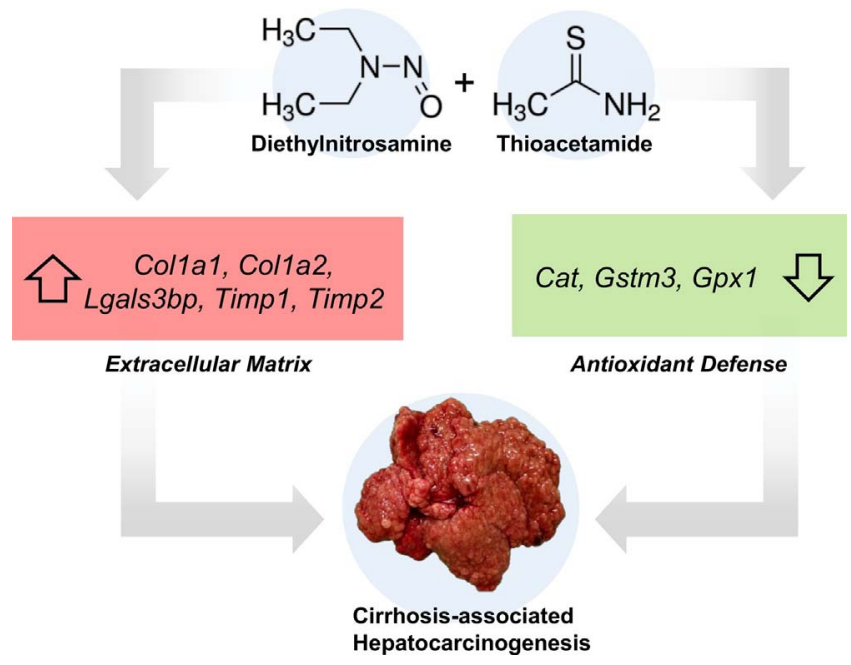

Fig. 6. The main genes modulated by DEN/TAA during cirrhosis-associated hepatocarcinogenesis, considered potential molecular targets for preventive and therapeutic approaches. 


\section{Acknowledgements}

Luis F. Barbisan was the recipient of support research from FAPESP (2010/14110-4 for supplies of microarray analysis). The authors thank Paulo César Georgete for the technical support during the experimental period.

\section{Appendix A. Supplementary data}

Supplementary data associated with this article can be found, in the online version, at http://dx.doi.org/10.1016/j.toxlet.2017.09.015.

\section{References}

Aycock, R.S., Seyer, J.M., 1989. Collagens of normal and cirrhotic human liver. Connect. Tissue Res. 23, 19-31.

Bakiri, L., Wagner, E.F., 2013. Mouse models for liver cancer. Mol. Oncol. 7, 206-223. Benyon, R.C., Hovell, C.J., Da Gaça, M., Jones, E.H., Iredale, J.P., Arthur, M.J., 1999. Progelatinase A is produced and activated by rat hepatic stellate cells and promotes their proliferation. Hepatology 30, 977-986.

Bergmeyer, H.U., 1974. Methods of Enzymatic Analysis, Academic Press, New York.

Bernardo, M.M., Fridman, R., 2003. TIMP-2 (tissue inhibitor of metalloproteinase-2) regulates MMP-2 (matrix metalloproteinase-2) activity in the extracellular environment after pro-MMP-2 activation by MT1 (membrane type 1)-MMP. Biochem. J. 374, 739-745.

Bonacchi, A., Petrai, I., Defranco, R.M.S., Lazzeri, E., Annunziato, F., Efsen, E., Cosmi, L., Romagnani, P., Milani, S., Failli, P., Batignani, G., Liotta, F., Laffi, G., et al., 2003. The chemokine CCL21 modulates lymphocyte recruitment and fibrosis in chronic hepatitis C. Gastroenterology 125, 1060-1076.

Bonnans, C., Chou, J., Werb, Z., 2014. Remodelling the extracellular matrix in development and disease. Nat. Rev. Mol. Cell Biol. 15, 786-801.

Brigelius-Flohé, R., Maiorino, M., 2013. Glutathione peroxidases. Biochim. Biophys. Acta 1830, 3289-3303.

Chan, K.-M., Wu, T.-H., Wu, T.-J., Chou, H.-S., Yu, M.-C., Lee, W.-C., 2016. Bioinformatics microarray analysis and identification of gene expression profiles associated with cirrhotic liver. Kaohsiung J. Med. Sci. 32, 165-176. http://dx.doi.org/10.1016/j. kjms.2016.03.008.

Chelikani, P., Fita, I., Loewen, P.C., 2004. Diversity of structures and properties among catalases. Cell Mol. Life Sci. 61, 192-208.

Cichoż-Lach, H., Michalak, A., 2014. Oxidative stress as a crucial factor in liver diseases. World J. Gastroenterol. 20, 8082.

Czeczot, H., Scibior, D., Skrzycki, M., Podsiad, M., 2006. Glutathione and GSH-dependent enzymes in patients with liver cirrhosis and hepatocellular carcinoma. Acta Biochim. Pol. 53, 237-242.

Czuczejko, J., Zachara, B.A., Staubach-topczewska, E., 2003. Selenium, glutathione and glutathione peroxidases in blood of patients with chronic liver diseases. Acta Biochim. Pol. 50, 85-92.

De Minicis, S., Kisseleva, T., Francis, H., Baroni, G.S., Benedetti, A., Brenner, D., Alvaro, D., Alpini, G., Marzioni, M., 2013. Liver carcinogenesis: rodent models of hepatocarcinoma and cholangiocarcinoma. Dig. Liver Dis. 45, 450-459.

Edgar, R., Domrachev, M., Lash, A.E., 2002. Gene Expression Omnibus: NCBI gene expression and hybridization array data repository. Nucleic Acids Res. 30, 207-210.

Fowell, A.J., Collins, J.E., Duncombe, D.R., Pickering, J a., Rosenberg, W.M.C., Benyon, R.C., 2011. Silencing tissue inhibitors of metalloproteinases (TIMPs) with short interfering RNA reveals a role for TIMP-1 in hepatic stellate cell proliferation. Biochem. Biophys. Res. Commun. 407, 277-282.

Fresno, C., Fernández, E.A., 2013. RDAVIDWebService. a versatile $r$ interface to DAVID. Bioinformatics 29, 2810-2811.

Furtado, K.S., Pires, P.W., Justulin, L.A., Rodrigues, M.A.M., Felisbino, S.L., Barbisan, L.F., 2009. Metalloproteinases 2 and -9 activity during promotion and progression stages of rat liver carcinogenesis. J. Mol. Histol. 40, 1-11.

Furtado, K.S., Prado, M.G., Aguiar e Silva, M.A., Dias, M.C., Rivelli, D.P., Rodrigues, M.A.M., Barbisan, L.F., 2012. Coffee and caffeine protect against liver injury induced by thioacetamide in male wistar rats. Basic Clin. Pharmacol. Toxicol. 111, 339-347.

GLOBOCAN, 2013. GLOBOCAN 2012 v1.0 Cancer Incidence and Mortality Worldwide: IARC CancerBase No. 11. International Agency for Research on Cancer, Lyon, France. http://globocan.iarc.fr.

Gelse, K., Pöschl, E., Aigner, T., 2003. Collagens - structure, function, and biosynthesis. Adv. Drug Deliv. Rev. 55, 1531-1546.

Gollmer, K., Asperti-boursin, F., Tanaka, Y., Okkenhaug, K., Peterson, J.R., Fukui, Y., Donnadieu, E., Stein, J.V., 2009. CCL21 mediates CD4 + T-cell costimulation via a DOCK2/Rac-dependent pathway. Blood 114, 580-588.

Habig, W.H., Pabst, M.J., Jakoby, W.B., 1974. Glutathione S-transferases The first enzymatic step in mercapturic acid formation. J. Biol. Chem. 25, 7130-7139.

Han, Y.P., Yan, C., Zhou, L., Qin, L., Tsukamoto, H., 2007. A matrix metalloproteinase-9 activation cascade by hepatic stellate cells in trans-differentiation in the three-dimensional extracellular matrix. J. Biol. Chem. 282, 12928-12939.

Hanahan, D., Weinberg, R.A., 2011. Hallmarks of cancer: the next generation. Cell 144, 646-674.

Henderson, N.C., Mackinnon, A.C., Farnworth, S.L., Poirier, F., Russo, F.P., Iredale, J.P., Haslett, C., Simpson, K.J., Sethi, T., 2006. Galectin-3 regulates myofibroblast activation and hepatic fibrosis. Proc. Natl. Acad. Sci. U. S. A. 103, 5060-5065.

Hsu, D.K., Dowling, C.A., Jeng, K.C.G., Chen, J.T., Yang, R.Y., Liu, F.T., 1999. Galectin-3 expression is induced in cirrhotic liver and hepatocellular carcinoma. Int. J. Cancer 81, 519-526.

Ito, N., Hasegawa, R., Imaida, K., Hirose, M., Shirai, T., 1996. Medium-term liver and multi-organ carcinogenesis bioassays for carcinogens and chemopreventive agents. Exp. Toxicol. Pathol. 48, 113-119.

Ito, N., Imaida, K., Asamoto, M., Shirai, T., 2000. Early detection of carcinogenic substances and modifiers in rats. Mut. Res. 462, 209-217.

Ji, J., Yu, F., Ji, Q., Li, Z., Wang, K., Zhang, J., Lu, J., E, Q., Ji, Y., 2012. Comparative proteomic analysis of rat hepatic stellate cell activation: a comprehensive view and suppressed immune response. Hepatology 56, 332-349.

Jiang, Z.Y., Woollard, A., Wolff, S., 1991. Lipid hydroperoxide measurement by oxidation of $\mathrm{Fe}^{3+}$ in the presence of xylenol orange. Lipids 26, 853-856.

Kang, J.S., Wanibuchi, H., Morimura, K., Wongpoomchai, R., Chusiri, Y., Gonzalez, F.J., Fukushima, S., 2008. Role of CYP2E1 in thioacetamide-induced mouse hepatotoxicity. Toxicol. Appl. Pharmacol. 228, 295-300.

Klein, T., Bischoff, R., 2011. Physiology and pathophysiology of matrix metalloproteases. Amino Acids 41, 271-290.

Konishi, M., Iwasa, M., Araki, J., Kobayashi, Y., Katsuki, A., Sumida, Y., Nakagawa, N., Kojima, Y., Watanabe, S., Adachi, Y., Kaito, M., 2006. Increased lipid peroxidation in patients with non-alcoholic fatty liver disease and chronic hepatitis $\mathrm{C}$ as measured by the plasma level of 8-isoprostane. J. Gastroenterol. Hepatol. 21, 1821-1825.

Li, T., Zhao, X.P., Wang, L.Y., Gao, S., Zhao, J., Fan, Y.C., Wang, K., 2013. Glutathione Stransferase P1 correlated with oxidative stress in hepatocellular carcinoma. Int. J. Med. Sci. 10, 683-690. http://dx.doi.org/10.7150/ijms.5947.

Liu, L., Cara, D.C., Kaur, J., Raharjo, E., Mullaly, S.C., Jongstra-Bilen, J., Jongstra, J., Kubes, P., 2005. LSP1 is an endothelial gatekeeper of leukocyte transendothelial migration. J. Exp. Med. 201, 409-418.

Liu, Y.-F., Zha, B.-S., Zhang, H.-L., Zhu, X.-J., Li, Y.-H., Zhu, J., Guan, X.-H., Feng, Z.-Q., Zhang, J.-P., 2009. Characteristic gene expression profiles in the progression from liver cirrhosis to carcinoma induced by diethylnitrosamine in a rat model. J. Exp. Clin. Cancer Res. 28, 107.

Low, T.Y., Leow, C.K., Salto-Tellez, M., Chung, M.C., 2004. A proteomic analysis of thioacetamide-induced hepatotoxicity and cirrhosis in rat livers. Proteomics 4, 3960-3974.

Maeda, H., Okamoto, T., Akaike, T., 1998. Human matrix metalloprotease activation by insults of bacterial infection involving proteases and free radicals. Biol. Chem. 379, 193-200.

Marsland, B.J., Bättig, P., Bauer, M., Ruedl, C., Lässing, U., Beerli, R.R., Dietmeier, K., Ivanova, L., Pfister, T., Vogt, L., Nakano, H., Nembrini, C., Saudan, P., et al., 2005. CCL19 and CCL21 induce a potent proinflammatory differentiation program in licensed dendritic cells. Immunity 22, 493-505.

Mizukami, S., Ichimura, R., Kemmochi, S., Taniai, E., Shimamoto, K., Ohishi, T., Takahashi, M., Mitsumori, K., Shibutani, M., 2010. Induction of GST-P-positive proliferative lesions facilitating lipid peroxidation with possible involvement of transferrin receptor up-regulation and ceruloplasmin down-regulation from the early stage of liver tumor promotion in rats. Arch. Toxicol. 84, 319-331.

Mochida, Y., Parisuthiman, D., Pornprasertsuk-Damrongsri, S., Atsawasuwan, P., Sricholpech, M., Boskey, A.L., Yamauchi, M., 2009. Decorin modulates collagen matrix assembly and mineralization. Matrix Biol. 28, 44-52.

Mohammad, H.S., Kurokohchi, K., Yoneyama, H., Tokuda, M., Morishita, A., Jian, G., Shi, L., Murota, M., Tani, J., Kato, K., Miyoshi, H., Deguchi, A., Himoto, T., Usuki, H., Wakabayashi, H., Izuishi, K., Suzuki, Y., Iwama, H., Deguchi, K., Uchida, N., Sabet, E.A., Arafa, U.A., Hassan, A.T., El-Sayed, A.A., Masaki, T., 2008. Annexin A2 expression and phosphorylation are up-regulated in hepatocellular carcinoma. Int. J. Oncol. 33 (6), 1157-1163.

Mokdad, A.A., Lopez, A.D., Shahraz, S., Lozano, R., Mokdad, A.H., Stanaway, J., Murray, C.J.L., Naghavi, M., 2014. Liver cirrhosis mortality in 187 countries between 1980 and 2010: a systematic analysis. BMC Med. 12, 145.

Moles, A., Tarrats, N., Fernández-Checa, J.C., Marí, M., Cathepsins, B., 2009. D drive hepatic stellate cell proliferation and promote their fibrogenic potential. Hepatology 49, 1297-1307.

Nakamura, W., Hojoda, S., Hayashi, K., 1974. Purification and properties of rat liver glutathione peroxidase. Biochim. Biophys. Acta 358, 251-261.

National Research Council, 2011. National research council (US) committee for the update of the guide for the care and use of laboratory animals. Guide for the Care and Use of Laboratory Animals. National Academies Press, Washington, DC.

Nie, Q.H., Cheng, Y.Q., Xie, Y.M., Zhou, Y.X., Bai, X.G., Cao, Y.Z., 2002. Methodologic research on TIMP-1 TIMP-2 detection as a new diagnostic index for hepatic fibrosis and its significance. World J. Gastroenterol. 8, 282-287.

Ogawa, K., 2009. Molecular pathology of early stage chemically induced hepatocarcinogenesis. Pathol. Int. 59, 605-622.

Ozer, J., Ratner, M., Shaw, M., Bailey, W., Schomaker, S., 2008. The current state of serum biomarkers of hepatotoxicity. Toxicology 245, 194-205.

Power, C., Sinha, S., Webber, C., Manson, M.M., Neal, G.E., 1987. Transformation related expression of glutathione-s-transferase $\mathrm{p}$ in rat liver cells. Carcinogenesis 8, 797-801.

Préaux, A.M., Mallat, A., Nhieu, J.T., D’Ortho, M.P., Hembry, R.M., Mavier, P., 1999. Matrix metalloproteinase- 2 activation in human hepatic fibrosis regulation by cellmatrix interactions. Hepatology 30, 944-950.

Pratico, D., Iuliano, L., Basili, S., Ferro, D., Camastra, C., Cordova, C., FitzGerald, G.A., Violi, F., 1998. Enhanced lipid peroxidation in hepatic cirrhosis. J. Investig. Med. 46, 51-57.

Qi, Y., Chen, X., Chan, C., Li, D., Yuan, C., Yu, F., Lin, M.C., Yew, D.T., Kung, H.-F., Lai, L., 2008. Two-dimensional differential gel electrophoresis/analysis of diethylnitrosamine induced rat hepatocellular carcinoma. Int. J. Cancer 122, 2682-2688. 
Ra, H.J., Parks, W.C., 2007. Control of matrix metalloproteinase catalytic activity. Matrix Biol. 26, 587-596.

Ritchie, M.E., Phipson, B., Wu, D., Hu, Y., Law, C.W., Shi, W., Smyth, G.K., 2015. Limma powers differential expression analyses for RNA-sequencing and microarray studies. Nucleic Acids Res. 43, e47.

Sanyal, A.J., Yoon, S.K., Lencioni, R., 2010. The etiology of hepatocellular carcinoma and consequences for treatment. Oncologist 15, 14-22.

Scaglione, S., Kliethermes, S., Cao, G., Shoham, D., Durazo, R., Luke, A., Volk, M.L., 2015. The epidemiology of cirrhosis in the United States: a population-based study. J. Clin. Gastroenterol. 49, 690-696.

Schäfer, G., Hitchcock, J.K., Shaw, T.M., Katz, A a., Parker, M.I., 2015. A novel role of annexin A2 in human type i collagen gene expression. J. Cell. Biochem. 116, 408-417.

Schönbeck, U., Mach, F., Libby, P., 1998. Generation of biologically active IL-1 beta by matrix metalloproteinases: a novel caspase-1-independent pathway of IL-1 beta processing. J. Immunol. 161, 3340-3346.

Shen, L.J., Zhang, H.X., Zhang, Z.J., Li, J.Y., Chen, M.Q., Yang, W.B., Huang, R., 2003. Detection of HBV, PCNA and GST-pi in hepatocellular carcinoma and chronic liver diseases. World J. Gastroenterol. 9, 459-462.

Shen, H., French, B.A., Liu, H., Tillman, B.C., French, S.W., 2014. Increased activity of the complement system in the liver of patients with alcoholic hepatitis. Expl. Mol. Pathol. 97, 338-344.

Staňková, P., Kučera, O., Lotková, H., Roušar, T., Endlicher, R., Červinková, Z., 2010. The toxic effect of thioacetamide on rat liver in vitro. Toxicol. In Vitro 24, 2097-2103.

Sun, F., Hayami, S., Ogiri, Y., Haruna, S., Tanaka, K., Yamada, Y., Tokumaru, S., Kojo, S., 2000. Evaluation of oxidative stress based on lipid hydroperoxide, vitamin C and vitamin $\mathrm{E}$ during apoptosis and necrosis caused by thioacetamide in rat liver. Biochim. Biophys. Acta 1500, 181-185.

Tatematsu, M., Tsuda, H., Shirai, T., Masui, T., Ito, N., 1987. Placental glutathione Stransferase (GST-P) as a new marker for hepatocarcinogenesis: in vivo short-term screening for hepatocarcinogens. Toxicol. Pathol. 15, 60-68.

Thoolen, B., Maronpot, R.R., Harada, T., Nyska, A., Rousseaux, C., Nolte, T., Malarkey, D.E., Kaufmann, W., Küttler, K., Deschl, U., Nakae, D., Gregson, R., Vinlove, M.P., Brix, A.E., Singh, B., Belpoggi, F., Ward, J.M., 2010. Proliferative and nonproliferative lesions of the rat and mouse hepatobiliary system. Toxicol. Pathol. 38, 5S-81S.

Townsend, D.M., Tew, K.D., 2003. The role of glutathione-S-transferase in anti-cancer drug resistance. Oncogene 22, 7369-7375.

Tsuda, H., Fukushima, S., Wanibuchi, H., Morimura, K., Nakae, D., Imaida, K., Tatematsu, M., Hirose, M., Wakabayashi, K., Moore, M.A., 2003. Value of GST-P positive preneoplastic hepatic foci in dose-response studies of hepatocarcinogenesis: evidence for practical thresholds with both genotoxic and nongenotoxic carcinogens. a review of recent work. Toxicol. Pathol. 31, 80-86.

Vasel, M., Rutz, R., Bersch, C., Feick, P., Singer, M.V., Kirschfink, M., Nakchbandi, I.A., 2014. Complement activation correlates with liver necrosis and fibrosis in chronic hepatitis C. Clin. Immunol. 150, 149-152.

Wallace, M.C., Hamesch, K., Lunova, M., Kim, Y., Weiskirchen, R., Strnad, P., Friedman, S.L., 2015. Standard operating procedures in experimental liver research: thioacetamide model in mice and rats. Lab. Anim. 49, 21-29.

Yang, J.D., Kim, W.R., Coelho, R., Mettler, T.A., Benson, J.T., Sanderson, S.O., Therneau, T.M., Kim, B., Roberts, L.R., 2011. Cirrhosis is present in most patients with hepatitis B and hepatocellular carcinoma. Clin. Gastroenterol. Hepatol. 9, 64-70.

Yanguas, S.C., Cogliati, B., Willebrords, J., Maes, M., Colle, I., van den Bossche, B., de Oliveira, C.P.M.S., Andraus, W., Alves, V.A., Leclercq, I., Vinken, M., 2015. Experimental models of liver fibrosis. Arch. Toxicol. 90, 1025-1048.

Yoshiji, H., Kuriyama, S., Miyamoto, Y., Thorgeirsson, U.P., Gomez, D.E., Kawata, M., Yoshii, J., Ikenaka, Y., Noguchi, R., Tsujinoue, H., Nakatani, T., Thorgeirsson, S.S. Fukui, H., 2000. Tissue inhibitor of metalloproteinases- 1 promotes liver fibrosis development in a transgenic mouse model. Hepatology 32, 1248-1254.

Yusof, Y.A., Yan, K.L., Hussain, S.N., 2003. Immunohistochemical expression of pi class glutathione S-transferase and alpha-fetoprotein in hepatocellular carcinoma and chronic liver disease. Anal. Quant. Cytol. Histol. 25 (6), 332-338.

Zhang, H., Yao, D., Yao, M., Huang, H., Wang, L., Yan, M., Yan, X., Gu, X., Wu, W., Lu, S., Zhang, H., Yao, D., Yao, M., Wang, L., 2013. Annexin A2 silencing inhibits invasion, migration,vand tumorigenic potential of hepatoma cells. World J. Gastroenterol. 19, 3792-3801.

Zhou, W.-C., 2014. Pathogenesis of liver cirrhosis. World J. Gastroenterol. 20, 7312.

Zindy, P., Andrieux, L., Bonnier, D., Musso, O., Langouët, S., Campion, J.P., Turlin, B., Clément, B., Théret, N., 2005. Upregulation of DNA repair genes in active cirrhosis associated with hepatocellular carcinoma. FEBS Lett. 579, 95-99.

Zusterzeel, P.L., Peters, W.H., De Bruyn, M.A., Knapen, M.E., Merkus, H.M., 1999. Glutathione S-transferase isoenzymes in decidua and placenta of preeclamptic pregnancies. Obstet. Gynecol. 94, 1033-1038. 